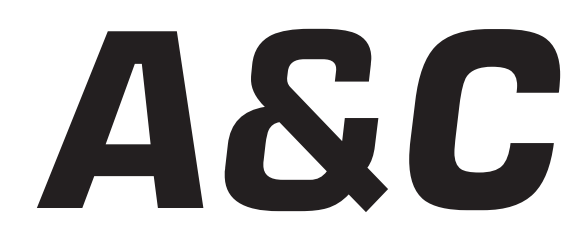

Revista de Direito Administrativo \& Constitucional

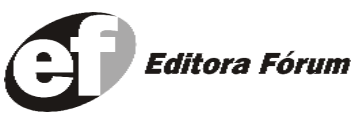

A\&C R. de Dir. Administrativo e Constitucional, Belo Horizonte, ano 6, n. 23, p. 1-253, jan./mar. 2006 


\section{A\&C REVISTA DE DIREITO ADMINISTRATIVO E CONSTITUCIONAL}

\section{IPDA}

Instituto Paranaense

de Direito Administrativo

Direção Geral

Romeu Felipe Bacellar Filho

Direção Editorial

Paulo Roberto Ferreira Motta

Direção Executiva

Emerson Gabardo

Conselho de Redação

Edgar Chiuratto Guimarães

Adriana da Costa Ricardo Schier

Célio Heitor Guimarães

Conselho Editorial

Adilson Abreu Dallari

Alice Gonzáles Borges

Carlos Ari Sundfeld

Carlos Ayres Britto

Carlos Delpiazzo

Cármen Lúcia Antunes Rocha

Celso Antônio Bandeira de Mello

Clèmerson Merlin Clève

Clóvis Beznos

Enrique Silva Cimma

Eros Roberto Grau

Fabrício Motta

Guilhermo Andrés Muñoz (in memoriam)

Jaime Rodríguez-Arana Muñoz

Jorge Luís Salomoni
José Carlos Abraão
José Eduardo Martins Cardoso

José Luís Said

José Mario Serrate Paz

Juan Pablo Cajarville Peruffo

Juarez Freitas

Julio Rodolfo Comadira

Luís Enrique Chase Plate

Lúcia Valle Figueiredo

Manoel de Oliveira Franco Sobrinho

(in memoriam)

Marçal Justen Filho

Marcelo Figueiredo

Márcio Cammarosano

Maria Cristina Cesar de Oliveira
Nelson Figueiredo

Odilon Borges Junior

Pascual Caiella

Paulo Eduardo Garrido Modesto

Paulo Henrique Blasi

Paulo Neves de Carvalho (in memoriam)

Paulo Ricardo Schier

Pedro Paulo de Almeida Dutra

Regina Maria Macedo Nery Ferrari

Rogério Gesta Leal

Rolando Pantoja Bauzá

Sérgio Ferraz

Valmir Pontes Filho

Yara Stropa

Weida Zancaner

\footnotetext{
A246 A\&C Revista de Direito Administrativo e Constitucional. ano 3, n. 11, jan./mar. 2003. Belo Horizonte: Fórum, 2003.

Trimestral

ano 1, n.1, 1999 até ano 2, n.10, 2002 publicada pela Editora Juruá em Curitiba

ISSN: 1516-3210

1. Direito Administrativo. 2. Direito Constitucional. I. Fórum.
}

CDD: 342 CDU: 33.342

(c) Editora Fórum Ltda. 2006

Todos os direitos reservados. É proibida a reprodução total ou parcial, de qualquer forma ou por qualquer meio eletrônico ou mecânico, inclusive através de processos xerográficos, de fotocópias ou de gravação, sem permissão por escrito do possuidor dos direitos de cópias (Lei $n^{\circ}$ 9.610, de 19.02.1998).

Editora Fórum Ltda

Av. Afonso Pena, 2770 - 15\%16ªndar - Funcionários

CEP 30130-007 - Belo Horizonte/MG - Brasil

Tel.: 08007043737

Internet: www.editoraforum.com.br

e-mail: editoraforum@editoraforum.com.br
Editor responsável: Luís Cláudio Rodrigues Ferreira Projeto gráfico e diagramação: Luis Alberto Pimenta Revisora: Olga M. A. Sousa

Pesquisa jurídica: Fátima Ribeiro - OAB/MG 74868

Bibliotecária: Nilcéia Lage de Medeiros

CRB 1545/MG 6a região

Os conceitos e opiniões expressas nos trabalhos assinados são de responsabilidade exclusiva de seus autores.

Impressa no Brasil / Printed in Brazil

Distribuída em todo Território Nacional 


\title{
Diálogo institucional como pressuposto da efetividade constitucional*
}

\author{
Vanice Regina Lírio do Valle \\ Doutoranda em Direito pela Universidade Gama Filho. Procuradora do Município do Rio de Janeiro. \\ Diretora do Departamento de Ciências Jurídicas da Universidade Gama Filho
}

\begin{abstract}
Sumário: 1 Introdução - 2 Contenção do abuso do poder - breve excurso histórico e a "tentação" do Judiciário - 3 Instituições político-estatais e sua inserção no modelo constitucional - 4 Caráter interdependente da conformação do sentido constitucional por cada qual das instituições sociopolíticas como premissa emanada do próprio Texto de Base - 5 Uma ilustração dos riscos: o juricentrismo constitucional traduzido como prática institucional de substituição e descarte - Referências
\end{abstract}

Palavras-chave: Abuso de poder, Brasil; Poder judiciário, Brasil; Ordenamento jurídico, Brasil ; Poder discricionário, Brasil ; Abuso do poder, contenção ; Instituições político-estatais ; Instituições sociopolíticaS.

\section{Introdução}

A intensificação dos debates relacionados à interface entre democracia e constitucionalismo, resgatando a consciência de um convívio, a rigor, no plano dos fatos, nunca interrompido, entre Direito e política, ${ }^{1}$ suscita novas questões relacionadas às fontes de (re)legitimação dos poderes políticos organizados, e dos caminhos de superação dos eventuais impasses, cada vez mais expostos publicamente com a expansão do papel da mídia, que, malgrè tout, ainda presta seus serviços à transparência. No grande ponto de confluência entre os dois conceitos acima mencionados, a jurisdição constitucional, como instrumento de preservação da estruturação social gizada pelo Texto Paradigma (no sentido mais amplo da expressão, compreendendo não só a organização do poder, mas também

\footnotetext{
* Estas considerações são desdobramento da reflexão iniciada no âmbito do Grupo de Pesquisa do Programa de Pós-Graduação em Direito da Universidade Gama Filho dedicado ao tema da jurisdição constitucional, que ensejou já o enfrentamento do tema do institucionalismo e seu papel na conformação da compreensão constitucional por ocasião dos estudos que resultaram na obra coletiva Teoria da Mudança Constitucional: sua Trajetória nos Estados Unidos e na Europa (VALLE, Vanice Regina Lírio do. Constitucionalismo Americano e a Incorporação Teórica dos Separation of Power Games. In: DUARTE, Fernanda; VIEIRA, José Ribas (Org.). Teoria da Mudança Constitucional: sua Trajetória nos Estados Unidos e na Europa. Rio de Janeiro: Renovar, 2005, p. 105-153). Registro ainda o agradecimento ao Prof. Dr. Marcos Juruena Vilela Souto, que, com seus comentários, contribui para o processo reflexivo da autora.

1 É de NOBRE a referência a um entrincheiramento mútuo entre o direito, e outras ciências humanas, bem como à circunstância de que "...quando os teóricos do direito são chamados para um consórcio interdisciplinar, eles vêm mais como consultores, para dizer qual o ponto de vista do Direito, que propriamente visando construir um diálogo, como ocorreu com outras disciplinas das Ciências Humanas" (NOBRE, Marcos. O Que é Pesquisa em Direito, Parte 1. In: NOBRE, MARCOS et. al. O Que é Pesquisa em Direito? São Paulo: Quartier Latin, 2005, p. 25-27).
} 
os direitos que ela assegura), traz sempre a polêmica relacionada à tensão, no seu exercício, entre Legislativo e Judiciário e, conseqüentemente, do critério de opção no que toca à prevalência, entre decisão (ainda que intermediada) dos representados, e aquela que emana de um órgão técnico não legitimado pelo voto.

A proposta, nas presentes considerações, é lançar um olhar distinto ao problema, reconhecendo que o desiderato de preservação da constituição deve determinar, não a polarização entre os poderes políticos, mas, ao revés, o estreitamento das relações, naquilo que se optou por denominar diálogo institucional.

Essas reflexões vêem à luz, à conta da visão mais difundida quanto ao fenômeno, que responde ao aparente impasse institucional entre Legislativo e Judiciário com uma solução binária, que reconheça, ao menos na hipótese concreta, a um ou outro, e com exclusividade, o papel de formatação da compreensão constitucional, com a desqualificação do remanescente. O que se sustenta é que esse caminho de solução conduz, por sua vez, à erosão constitucional, na medida em que formula juízos de prevalência no que toca à atuação institucional de uma das instâncias de poder, desfigurando uma complexa rede de atribuição de competências e responsabilidades que a própria Carta Fundamental traçou, acima de tudo, como mecanismo de adequação no exercício do poder, e prevenção quanto a desvios.

\section{Contenção do abuso do poder - breve excurso histórico e a "tentação" do Judiciário}

É a consciência das próprias necessidades, — “...vitais ou derivadas, reais ou imaginárias..." — ${ }^{2}$ projetadas como interesses, que move o homem a empregar sua capacidade de ação, exercitando portanto o poder (no sentido naturalístico) de que dispõe. A escalada de desenvolvimento desse mesmo homem lhe aponta, porém, vantagens para si da associação de esforços e iniciativas em favor de sua própria sobrevivência, e da potencialização de suas possibilidades produtivas. Em contraponto a esse conjunto de benefícios, pôs-se o problema de como se deveria estruturar essa coletividade, e quais os riscos a ela inerentes.

Resulta - potencialmente — da associação entre os homens que

2 MOREIRA NETO, Diogo de Figueiredo. O Homem e a Política. Atitudes ante o Poder: uma Contribuição à Democracia. Rio de Janeiro: Forense, 1987, p. XV.

A \& C R. de Dir. Administrativo e Constitucional, Belo Horizonte, ano 6, n. 23, p. 189-206, jan./mar. 2006 
esse mesmo poder que se exerce sobre as coisas possa vir a ser exercido sobre os demais, no sentido que Bobbio e Matteucci associam à expressão poder social. ${ }^{3}$ Com isso, o tema da organização do convívio em sociedade se relaciona, de início, e de forma inseparável, ao tema do poder.

Desenha-se assim um mecanismo sempre percorrido de um modelo de estruturação da coletividade que, tendo em conta os riscos àquela mesma sociedade, aponte um caminho de solução, normalmente traduzido em distribuição de poder segundo a qual o abuso se veja, se não inteiramente bloqueado, ao menos mitigado nas suas possibilidades. Máximo de benefício, com o mínimo de risco - essa a equação perseguida no mister de organização daquilo que depois viria a se identificar por Estado.

Essa escalada teórica tem início na elaboração de Hobbes, que, se de um lado tem em conta que “...a preocupação com a sua própria conservação e com uma vida mais satisfeita..." ${ }^{\prime 4}$ se revelará como elemento mobilizador à instituição do Estado - o autor usa a expressão República — como poder politicamente organizado; de outro lado “...somente investindo todo o poder num lugar só, e não o dividindo de forma alguma, é que será possível enfrentar a guerra de todos contra todos, em suma, que será viável evitar a morte violenta, e quem sabe, o fim da espécie humana...". ${ }^{5}$

Concentração de poder, como a alternativa de salvação ao homem, é tese logo refutada — ainda que sem referência expressa ao autor — por Locke, que, buscando na razão o fundamentos para a opção humana em favor da associação, assenta no consentimento o pilar a partir do qual se extrairá a conseqüência de que não possa estar o homem “... submetido a nenhum outro poder legislativo senão àqueles estabelecido no corpo político mediante consentimento, nem sob o domínio de qualquer vontade ou sob a restrição de qualquer lei afora as que promulgar o legislativo, segundo o encargos a este confiado". ${ }^{6}$

Distribuição de poder, — Locke não rejeita a existência do soberano,

\footnotetext{
3 BOBBIO, Norberto; MATTEUCCI, Nicola; PASQUINO, Gianfranco. Dicionário de Política. Trad.: Carmen C. Varriale... et. al. 5. ed. São Paulo: Ed. Universitária de Brasília, 2000, p. 934. Traduzido de Dizionaria di Política.

4 HOBBES, Thomas. Leviatã. Trad.: João Paulo Monteiro, Maria Beatriz Nizza da Silva, Claudia Berliner; revisão da tradução Eunice Ostrensky. São Paulo: Martins Fontes, 2003, p. 143. Traduzido de Leviathan.

5 A referência é ao prefácio de Janine Ribeiro, introduzindo, na versão brasileira, a obra "Diálogo entre um filósofo e um jurista" (HOBBES, Thomas. Diálogo entre um Filósofo e um Jurista. 2. ed. Trad.: Maria Cristina Guimarães Cupertino, Prefácio Renato Janine Ribeiro. São Paulo: Landy Editora, 2004, p. 21. Traduzido de A Dialogue Between a Philosopher and Student of Common Law of England.).

6 LOCKE, John. Dois Tratados sobre o Governo. Trad.: Julio Fischer. São Paulo: Martins Fontes, 1998, p. 402. Traduzido de Two Treaties of Government.
} 
instância igualmente de poder, a quem reconhece inclusive aquilo que denomina prerrogativas - com supremacia do legislativo, pelo que ele traduz de canal de expressão do titular do poder (o povo), é o modelo sugerido e disseminado, que encontra eco inclusive na elaboração teórica de Montesquieu.

Em que pese a polêmica envolvida no verdadeiro sentido da compreensão da proposta do Barão de Bréde, ${ }^{7}$ remanesce validada pela história sua afirmação segundo a qual a prevenção do abuso do poder residiria justamente na imposição por cada um deles, de limites à atuação do outro. ${ }^{8}$ Temperamento à supremacia de qualquer dos poderes é o elemento que agrega o autor francês, inspirado pelas observações que empreendera em sistemas vigentes em países distintos do seu de origem.

Do percurso já empreendido, é possível apontar a percepção de que a concentração do poder em qualquer de suas estruturas formais de organização não se revela opção apta à prevenção de seu exercício abusivo. Afinal, ainda que o deslocamento das "preferências" teóricas quanto ao locus da concentração da potência, do executivo (soberano) para o legislativo, tenha sido apontado como um caminho de solução, ${ }^{9}$ a vivência do seu exercício evidencia a "experiência eternal", a que se refere Montesquieu, da tendência ao abuso.

Essa percepção é igualmente corroborada por Seyés, que tendo já à vista a experiência francesa com seu próprio legislativo no período revolucionário, assevera “...a esta necessidade de organizar o corpo do governo, se quisermos que ele exista ou que aja, é necessário acrescentar o interesse que a nação tem em que o poder público delegado não possa nunca chegar a ser nocivo a seus comitentes". ${ }^{10}$

Caminha a conclusão, portanto, no sentido de que a pretensão de supremacia de qualquer dos poderes políticos organizados não só não se

7 É de Laurent Versini, subscritor da introdução à versão das edições Gallimard, a observação de que uma das fontes de mal entendido reside na ambiguidade da palavra poder — que costuma ser identificada com a estrutura institucional, associada prioritariamente ao desempenho de uma determinada função estatal, quando o autor, ao contrário, ao referir a poder, tem em conta, justamente, o corte funcional.

8 O texto clássico, expressão máxima dessa idéia, está contido no Livro XI, Capítulo IV, parte final de L’Esprit des Lois: "...La liberte politique ne se trouve que dans les gouvernments moderes. Mais elle n'est pás toujours dans les Etats modérés; elle n'y est que lorsqu'on n'abuse pas du pouvoir; mais c'est uma expérience éternelle que tout homme qui a du pouvoir est porte à em abuser; il va jusqu'à ce qu'il trouve dês limites. Qui le dirait! la vertu même a besoin des limites".

"Pour qu'on ne puisse abuser du pouvoir, il faut que, par la disposition des choses, le pouvoir arrête le pouvoir" (MONTESQUIEU. De l'esprit des Lois. Paris: Éditions Gallimard, 1995, p. 325-326).

9 É de TROCKER a referência que, no contexto histórico de evolução, o alcance por parte, especialmente, da burguesia, de acesso ao poder legislativo, conferira a (falsa) impressão de que os riscos residiriam no exercício inadequado ou abusivo do poder executivo, esse sim ainda fora de alcance (TROCKER, Nicolò. Le Omissioni del Legislatore e la Tutela Giurisdizionale dei Diritti di Libertà. Archivio Giuridico, v. 160, 1961, p. 210 et seq.).

${ }^{0}$ SEYĖS, Emanuel Joseph. A Constituinte Burguesa: qu'est-ce que lê Tiers État? Trad.: Norma Azevedo. Rio de Janeiro: Lúmen Júris, 2001, p. 48. 
revelou suficiente à geração do efeito pretendido de prevenção do abuso; como, no mais das vezes, culminou por evidenciar que cada qual deles, investido de uma suposta condição de superioridade, tendia - como já advertia Montesquieu - ao abuso.

Essa evidência histórica revela-se particularmente útil em um momento em que, à conta da própria reconfiguração do que se possa ter por constituição, impulsionada por toda a elaboração teórica do chamado período pós- $45,{ }^{11}$ desponta em importância o Poder Judiciário, particularmente através do exercício da jurisdição constitucional, nessa equação de exercício e equilíbrio de poderes. Assim é que, se, de um lado, o fortalecimento da dimensão teórica do novo constitucionalismo apresenta ao Judiciário as possibilidades relacionadas à interpretação e à garantia de efetividade da constituição; de outro lado, decerto, revela-se um ponderável fator de risco de que sucumba esse mesmo Judiciário, à tentação do poder, assim como já o fizeram estruturas de poder político mais afeitas ao trânsito nessa seara.

O alcance que as novas compreensões relacionadas aos direitos fundamentais que emanam do Texto de Base, sua exigibilidade, e mais recente, sua horizontalidade, confere à instituição detentora da palavra final quanto à observância e concretização da constituição um enorme espectro de atuação - e, portanto, de possível exercício de poder. E se, como advertia Montesquieu, mesmo a virtude tem necessidade de limites, o que dizer em relação ao Judiciário? Indispensável a percepção dos riscos inerentes ao exercício da função que a configuração constitucional lhe atribuiu; não num caminho de apequenamento de seu próprio papel institucional, mas de aprimoramento da compreensão desse mesmo papel em sua inteireza.

\footnotetext{
11 Evita-se, propositadamente, a referência a neoconstitucionalismo, expressão que vem já despertando acirrada polêmica no que toca a seu alcance e suas relação com o pós-positivismo, polêmica que não se revela útil à idéia a cuja exposição se dedica o presente trabalho.
} 
12 HALL, Peter A.; TAYLOR, Rosemary C. R.. As Três Visões do Neoinstitucionalismo, Revista Lua Nova [online]., n. 58, 2003 p.193-223. Disponível em: <http://www.scielo.br/scielo.php?script=sci_arttext\&pid=S010264452003000100010\&lng=en\&nrm=iso >. Acesso em: 3 dez. 2005.

13 THERET, Bruno. As Instituições entre as Estruturas e as Ações. Revista Lua Nova. [online], n. 58, 2003, p.225-254. Disponível em: <http://www.scielo.br/scielo.php?script=sci_arttext\&pid=S010264452003000100011\&lng=en\&nrm=iso > . Acesso em: 30 nov. 2005.

${ }^{14} \mathrm{O}$ tema dos mecanismos e perspectivas, através dos quais cada instituição promova as suas escolhas, se constitui foco de intenso debate no que toca ao institucionalismo em si, permitindo classificações e sua crítica, tudo no sentido de se compreender como se dê, seja o surgir das instituições, seja seu processo decisório. Assim é que a ótica historicista, aquela que vê na escolha racional o caminho de decisão, e, finalmente, aquelas vinculadas ao caráter sociológico ou cultural das instituições são abordagens que

A \& C R. de Dir. Administrativo e Constitucional, Belo Horizonte, ano 6, n. 23, p. 189-206, jan./mar. 2006 
permitem essa mesma investigação acerca de como se dá o processo de agregação e decisão coletiva, e, mais ainda, quais os mecanismos de influências recíprocas entre indivíduos e instituições.

15 HALL, Peter A.; TAYLOR, Rosemary C. R. As Três Visões..., p. 197.

A \& C R. de Dir. Administrativo e Constitucional, Belo Horizonte, ano 6, n. 23, p. 189-206, jan./mar. 2006 
16 É de Post a referência a que estados democráticos incorporam o valor da autogovernança coletiva, que demanda que os cidadãos venham a identificar sua própria autoria das ações estatais e escolhas; ou, ao menos, sua participação potencial nos procedimentos deliberativos através dos quais esse mesmo estado alcança suas decisões (POST, Robert. Democratic Constitutionalism and Cultural Heterogeneity. UC Berkeley Public Law and Legal Theory Working Paper Series. Disponível em: <http://www.papers.ssrn.com/ paper.taf?abstract id=229161 > . Acesso em: $16 \mathrm{dez}$. 2005)

17 LOEWENSTEIN, Karl. Teoría de la Constitución. 4. reimpr. Barcelona, España: Ariel Derecho, 1986, p. 24.

18 É também de Loewenstein a referência ao equívoco da pretensão dos modelos teóricos do período préindustrial, de que, racionalizando o exercício do poder, pudessem com isso "...escindir el Leviatán para dominarlo..." (LOEWENSTEIN, Karl. Teoría de la Constitución..., p. 61).

A \& C R. de Dir. Administrativo e Constitucional, Belo Horizonte, ano 6, n. 23, p. 189-206, jan./mar. 2006 
${ }^{19}$ É de Moreira Neto a referência pioneira ao caráter essencial — sob o prisma do controle — do cumprimento satisfatório da constituição na órbita da Administração Pública, e do elemento fundamental para esse mister, a saber, "...empregar efetivamente o relegado e desdenhado instrumento previsto pelo constituinte para a realização do difícil, delicado e permanente controle interno de juridicidade da administração pública: as instituições da Advocacia de Estado" (MOREIRA NETO, Diogo de Figueiredo. Independência Técnico-funcional da Advocacia de Estado. In: TAVARES, Lucia Léa Guimarães (Coord.). Revista de Direito da Associação dos Procuradores do Novo Estado do Rio de Janeiro, Advocacia Pública, v. XVI 2005, p. 11).

${ }^{20}$ Consulte-se, no tema, VALLE, Vanice Regina Lírio do. Controle Social: Promovendo a Aproximação entre Administração Pública e a Cidadania. Prêmio Serzedello Corrêa 2001: Monografias Vencedoras: Perspectivas para o Controle Social e a Transparência da Administração Pública. Brasília: TCU, Instituto Serzedello Corrêa, 2002, p. 89-94.

${ }^{21}$ SOUZA, Márcia Teixeira de. O Processo Decisório na Constituição de 1988: Práticas Institucionais. Revista Lua Nova. [online], n. 58, 2003, p. 37-59. Disponível em: <http://www.scielo.br/scielo.php?script= sci_arttext\&pid=S0102-64452003000100004\&lng=en\&nrm=iso >. Acesso em: 5 dez. 2005.

A \& C R. de Dir. Administrativo e Constitucional, Belo Horizonte, ano 6, n. 23, p. 189-206, jan./mar. 2006 
22 Ainda que se possa apontar essa dissociação entre uma estrutura institucional ambiciosa e o querer ou mesmo o histórico da sociedade brasileira recém-reencontrada com a democracia, fato é que também a circunscrição da proposta constitucional a modelos mais modestos jamais teria o condão de trazer à discussão justamente a necessidade de se construir essa prática institucional inexistente.

${ }^{23}$ Registre-se ainda a inoportunidade de se pretender inaugurar a prática do diálogo institucional através de preceito constitucional, e em tema de tamanha sensibilidade corporativa...

A \& C R. de Dir. Administrativo e Constitucional, Belo Horizonte, ano 6, n. 23, p. 189-206, jan./mar. 2006 
${ }^{24}$ Utiliza-se a expressão instituição controlada no sentido daquela geradora da decisão que se materializa em ato sujeito ao crivo por intermédio do exercício da jurisdição constitucional.

A \& C R. de Dir. Administrativo e Constitucional, Belo Horizonte, ano 6, n. 23, p. 189-206, jan./mar. 2006 
$25 \mathrm{O}$ afastamento de parte da instituição originariamente incumbida do desempenho de determinado papel, dando ensejo à substituição por outra no suposto exercício do controle, gera uma diluição de fronteiras de responsabilidade, indesejável na medida em que enfraquece também as possibilidades de exercício de controle social, especialmente no plano político.

${ }^{26}$ A expressão juricentrismo constitucional é utilizada por Post e Siegel, no sentido de uma visão identificada pelos autores como emanada da Suprema Corte norte-americana (o texto data de 2002), que atribui ao Judiciário a exclusividade na função de guardião da Constituição, subordinando a possibilidade de atuação dos demais poderes no enforcement de seu texto ao reforço igualmente da interpretação jurisdicional do significado do Texto de Base (POST, Robert; SIEGEL, Reva B. Protecting tha Constitution from the People: Juricentric Restrictions on Section Five Power. University of California at Berkeley, School of Law \& Legal Theory Research Paper Series (Research Paper, n. 112) e Yale Law School, Public Law \& Legal Theory Research Paper Series (Research Paper, n. 32). Disponível em <http://ssrn.com/abstract_id=378500 >. Acesso em: 4 dez. 2005).

27 A expressão se utiliza aqui no sentido propugnado por Alexy, de direitos emanados de norma jusfundamentais, que se revelam tão importantes do ponto de vista do direito constitucional, que sua outorga ou denegação não pode restar em mãos de uma simples maioria parlamentar (ALEXY, Robert. Teoría de los Derechos Fundamentales. 3. reimpr. Madrid: España: Centro de Estudios Políticos y Constitucionales, 2002, p. 435).

A \& C R. de Dir. Administrativo e Constitucional, Belo Horizonte, ano 6, n. 23, p. 189-206, jan./mar. 2006 


\footnotetext{
${ }^{28}$ Não se enfrenta aqui o tormentoso tema dos limites do dever do Estado no que toca a esses sensíveis direitos fundamentais sociais, eis que não constitui questão prejudicial ao desenvolvimento da proposta que se formula.

${ }^{29}$ Sublinhe-se que nesse tema não é infrequente que a negativa de classificação como direito fundamental social, ou ainda o posicionamento secundário numa escala de prioridades de ação estatal, seja decorrente de juízo decisório que conjuga Executivo e Legislativo, quando menos, quando se tem em conta os instrumentos legislativos de programação da ação estatal compreendidos na tríade orçamentária.

30 É ainda de Alexy a observação de que se tenha, na concepcão formal de direitos fundamentais, uma colisão entre essa idéia-força e princípio democrático, trazendo à evidência o debate em torno dos limites à liberdade de conformação do legislador, vetor que exige, por óbvio, o exercício do diálogo institucional no seu enfrentamento (ALEXY, Robert. Teoría de los Derechos..., p. 432-433).

${ }^{31}$ Caminha no mesmo sentido a observação de Post, de que embora seja plenamente possível que a Corte Constitucional abrace uma compreensão que se revele em dessintonia com a ótica política convencional — e mesmo popularizada - essa sua decisão só prevalecerá se apta a gerar apoio democrático, problema cujo caminho de solução passará, necessariamente, pelo desenvolvimento de argumentação que, considerando a alternativa política tradicional, evidencie, e com força persuasória, sua inadequação. "...The prospect or resistence and transformativa appointments ensures that legal and politicial understandings of the Constitution remain in constant dialogue. Just as the Court's constitutional rulings can shape the nation's political life, so developments in democratic politics may have significant ramifications for the development of constitucional law" (POST, Robert. Protecting the Constitution..., p. 25-26).
}

A \& C R. de Dir. Administrativo e Constitucional, Belo Horizonte, ano 6, n. 23, p. 189-206, jan./mar. 2006 
A \& C R. de Dir. Administrativo e Constitucional, Belo Horizonte, ano 6, n. 23, p. 189-206, jan./mar. 2006 
A \& C R. de Dir. Administrativo e Constitucional, Belo Horizonte, ano 6, n. 23, p. 189-206, jan./mar. 2006 
32 GADAMER, Hans-Georg. Verdade e Método II: Complementos e Índice. Trad.: Ênio Paulo Giachini; Revisão da tradução de Márcia Sá Cavalcante-Schuback. Petrópolis: Vozes, 2002, p. 252.

A \& C R. de Dir. Administrativo e Constitucional, Belo Horizonte, ano 6, n. 23, p. 189-206, jan./mar. 2006 
A \& C R. de Dir. Administrativo e Constitucional, Belo Horizonte, ano 6, n. 23, p. 189-206, jan./mar. 2006 
A \& C R. de Dir. Administrativo e Constitucional, Belo Horizonte, ano 6, n. 23, p. 189-206, jan./mar. 2006 